\title{
Thinking well beyond diagnosis: a four-year evaluation of a cognitive changes education for breast cancer survivors
}

This article was published in the following Dove Press journal:

Nursing: Research and Reviews

Jacqueline B Vo'

Silvia Gisiger-Camata

Kayla A Lewis'

Timiya S Nolan ${ }^{2}$

Jennifer R Bail ${ }^{3}$

Bailey A Hendricks'

David E Vance

Karen Meneses ${ }^{1, \dagger}$

'School of Nursing, University of Alabama at Birmingham, Birmingham, AL, USA; ${ }^{2}$ College of Nursing, The Ohio State Univeristy, Columbus, OH, USA; ${ }^{3}$ Department of Nutrition Sciences, University of Alabama at Birmingham, Birmingham, AL, USA

${ }^{\dagger}$ Karen Meneses passed away on August 이, 2018
Correspondence: Silvia Gisiger-Camata School of Nursing, University of Alabama at Birmingham, 1720 2nd Avenue South, NB 302, Birmingham, AL 35294-1210, USA

Tel + I 2059758656

Email sgcamata@uab.edu
Purpose: Cognitive changes affect up to $75 \%$ of breast cancer survivors during treatment and $35 \%$ after treatment. There remains a paucity of cognitive change-focused education programs for breast cancer survivors. The Think Well: Healthy Living to Improve Cognitive Function program was developed to address cognitive changes in Alabama breast cancer survivors. The purpose of this article is to report program development and expansion over four years and attendees' program satisfaction.

Methods: A seven-step framework (identify, connect, assess, tailor, plan, deliver, and evaluate) was used to develop and implement the Think Well program. The 2-h seminars, tailored to each respective community, consisted of face-to-face lecture-style education grounded on an evidence-based curriculum. Seminars were assessed using surveys that focused on attendees' satisfaction and were delivered at the end of each Think Well seminar. The surveys were summarized using descriptive statistics.

Results: Over four years, 17 Think Well seminars were delivered to a total of 666 attendees, and 515 (77\% response rate) completed a survey. Of which, 151 reported to be breast cancer survivors, 209 family and friends, and 155 others. Think Well received mostly "good" or "excellent" ratings on all educational program components in the evaluation. After receiving feedback from attendees, the Think Well program was also adapted to create an interactive website.

Conclusion: Think Well seminars were well-received and provided cognitive changefocused cancer education for an underserved and diverse population. Implications include disseminating Think Well to a multi-state or national platform, implementing Think Well education using social media engagement, and collaborating with health-care professionals to provide cognitive change information.

Keywords: survivorship, community-based program, breast cancer, cognitive changes, chemo-brain, cancer education

\section{Introduction}

More than 250,000 women are expected to be diagnosed with breast cancer every year in the USA. ${ }^{1}$ With advances in treatments and screening, $89.7 \%$ of women are surviving five years, contributing to more than 3.5 million breast cancer survivors in the USA. ${ }^{1}$ While women are living longer with breast cancer, they may not be living better. Cognitive changes affect up to $75 \%$ of breast cancer survivors during treatment and up to $35 \%$ after completion of treatment. ${ }^{2}$ Cognitive changes can diminish work productivity and impact dayto-day living and quality of life among breast cancer survivors. ${ }^{3,4}$ Known to 
many survivors as "chemobrain" due to its association with chemotherapy, cognitive changes may occur as a result of multiple factors: cancer treatment (eg, chemotherapy, hormone therapy, or radiation), advancing age, menopause status, psychosocial issues (ie, anxiety, depression, fatigue, or depression), and/or medication regimens. $^{5-11}$

The neuropsychology literature clearly demonstrates that lifestyle activities and behavioral changes (ie, increasing physical activity, reducing stress) can support brain health and thus, improve one's ability to think. ${ }^{12-15}$ Summarizing this literature, Vance and colleagues proposed an intervention paradigm of how this brain health information can be used for adults who experience cognitive problems. ${ }^{16}$ In a format called Cognitive Prescriptions, patients are educated on how different lifestyle activities are important for brain health; they are then encouraged to make personalized behavioral goals that synergistically improves brain health and cognition. Behavioral goals include broad areas known to impact brain health and cognition including: 1) physical exercise/activity; 2) intellectual exercise/activity (ie, computerized cognitive training); 3) sleep hygiene; 4) substance use; 5) mood support (ie, avoiding anxiety/depression); 6) social engagement; and 7) nutrition (ie, consuming more fatty acids found in fish). This approach of educating people about how to improve their brain health through individualized programmatic lifestyle goals is known as multimodal cognitive interventions and has been proposed in older adults and those with HIV. ${ }^{17}$ Such an evidence-based approach can be an effective way to improve brain health literacy and is strongly encouraged in breast cancer survivors. ${ }^{17}$

Interventions aimed at remediating cognitive changes among breast cancer survivors vary in approach (ie, cognitive remediation, mind-body therapy, physical activity, pharmacological therapy), but evidence is still being compiled regarding their effectiveness. ${ }^{18}$ Current survivorship guidelines recommend validating survivors' concerns about cognitive changes, and encouraging healthy living strategies for symptom self-management; however, busy clinic schedules do not always allow the time needed. ${ }^{2,19}$ Community-based approaches demonstrate feasibility and acceptability in delivering cancer education (ie, cancer screening, prevention, and early detection) and may be applied to delivering education on cancer-related cognitive changes. ${ }^{20}$ In Alabama, cognitive changes education programs are lacking and are of great need among breast cancer survivors. $^{21}$
The Think Well: Healthy Living to Improve Cognitive Function program was developed in 2014, with support from Susan G. Komen North Central Alabama affiliate, to address a major survivorship need related to cognitive changes among breast cancer survivors. In Alabama, nearly 4,000 women are diagnosed with breast cancer annually. ${ }^{22}$ Think Well targeted priority counties within Alabama identified by Susan G. Komen North Central Alabama Community Profile Report. $^{23}$ These medically underserved counties have key indicators that show increased risk of becoming a vulnerable population and barriers to access to care, such as: 1) increased breast cancer incidence; 2) late-stage diagnosis; and 3 ) low social demographic indicators (ie, county poverty level, health outcomes and factors ranking, and health transportation shortage index score). ${ }^{23}$ The purpose of this article is to describe the Think Well's program development and expansion over four years, attendees' program satisfaction, and challenges experienced.

\section{Methods}

\section{Program description}

Think Well was reviewed and approved by the University of Alabama at Birmingham Institutional Review Board. Written participant consent was waived as only aggregate information was used, and data were not identifiable. Think Well was a nurse-led, community-based program that provided face-to-face educational seminars to breast cancer survivors and accompanying attendees, and extension via a website. A seven-step framework (Figure 1) was used to develop and implement Think Well. ${ }^{24}$ The seminars were 2-h events composed of a 45-min lecture with active discussion, time for questions, and networking lunch. For each event, our team of nurses identified and partnered with a community leader. Location of program delivery varied but included cancer centers and non-healthcare centers such as churches and community centers. The seminars were tailored to the expected audience and respective communities, and as such, each program varied in its style, while the education components were consistent.

The evidence-based education curriculum was threefold. First, cognitive change was defined and explained. Second, healthy living strategies to promote cognitive function were provided in the domains of physical activity, nutrition, stress management, and sleep. Third, coping strategies were provided including practical tips (eg, using a daily planner, making notes, setting reminders, and keeping things in the same place). ${ }^{25}$ The curriculum 


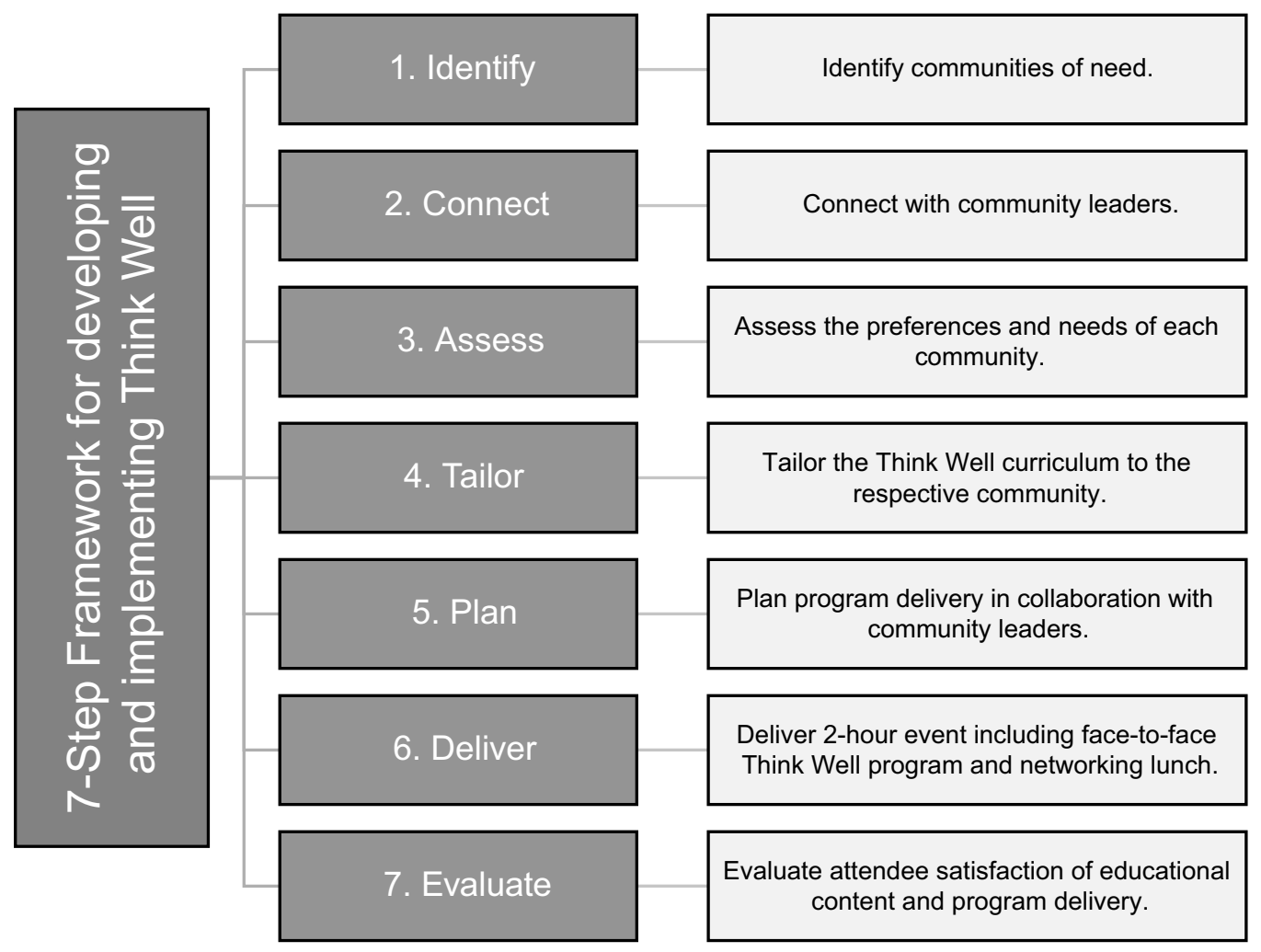

Figure I Seven-step framework for developing and implementing Think Well.

was derived from evidence-based literature and clinical guidelines from the National Comprehensive Cancer Network, American Cancer Society/American Society for Clinical Oncology, and Oncology Nursing Society Putting Evidence Practice. ${ }^{25} \mathrm{~A}$ take-home, eight-page tip sheet covering the seminar educational content was provided to reinforce and supplement live education. Educational materials discussed in seminars were tailored to each respective area and included examples and photos of local resources (eg, gyms, walking parks, farmer markets, and culturally appropriate images). Community partners identified free or low-cost resources in their area that were incorporated into each Think Well seminar.

\section{Program expansion}

In the first year of programming, Think Well was delivered to three African American churches in one urban county as described elsewhere. ${ }^{24}$ In the three subsequent years, Think Well expanded its outreach to a total of 17 seminars in three urban and six rural counties throughout Alabama. Think Well also added a website (www.ThinkWell.tips) in its second year in response to attendee feedback requesting online dissemination. The Think Well website served as an alternative method for attendees to receive supplementary information. Additionally, the Think Well curriculum was modified annually to reflect new or updated clinical guidelines.

\section{Program survey}

A survey (Table 1) assessing attendee demographics and program satisfaction was delivered at the end of each Think Well program to attendees 18 years and older. The questions asked about satisfaction with Think Well content, program delivery, and attendee demographics. Program delivery questions included: 1) how well each topic was covered; 2) the seminar met goals for attending; 3 ) the information was relevant for cognitive needs and cultural beliefs; 3 ) the information could be used to cope, and communicate cognitive concerns; 4) there was time for questions; 5) the overall quality of the seminar was satisfactory; and 6) facilities and refreshments were satisfactory. These questions used a 5-point Likert scale $(1=$ poor, not at all to $5=$ excellent, extremely). Attendee demographics assessed age, race, ethnicity, education, employment, income, marital status, and county of residence; variables with multiple categories were collapsed. Surveys were analyzed using descriptive statistics with SPSS Statistics (v25; IBM Corporation, Armonk, NY, USA). 
Table I Think Well survey questions

\begin{tabular}{|l}
\hline Program Satisfaction Questions \\
\hline How did you hear about this THINK WELL program? (Please check only one) \\
Email announcement, Flyer, Friend or Family Member, Social Media, Website, Other \\
\hline Please indicate which of the following categories best describes you (Please check only one): \\
Breast Cancer Survivor, Spouse of Breast Cancer Survivor, Family or Friend of Breast Cancer Survivor, \\
Health Professional Caring for Breast Cancer Survivors, Other \\
\hline $\begin{array}{l}\text { Please rate how well each topic was covered in the THINK WELL seminar on a scale I-5 of } \\
\text { (5=excellent to I=poor): } \\
\text { Cognitive Changes, Nutrition, Physical Activity, Stress Management, Compensatory (Coping) Strategies }\end{array}$
\end{tabular}

For the overall THINK WELL seminar, rate the following. Use the scale I-5 (5=excellent, I=poor):

Seminar met your goals for attending

Information received was relevant for your needs

Information received was relevant to your cultural beliefs

Ability to use the information you learned to help with coping

Ability to use information received to communicate cognitive concerns

Availability of time for questions

Overall quality of the seminar

Location of facilities

Refreshments provided

How likely is it that you would recommend this seminar to someone?

Not at all, Little, Moderately, Very Much, Extremely

Please indicate the best way to receive future THINK WELL education:

Online, Text Message, Telephone, Seminar format as today, Other

In the future, what themes around cognitive changes would you like to learn more about?

(open ended response)

List any other comments or suggestions about the THINK WELL program:

(open ended response)

Demographic Questions

How old are you?

_ years

What is your race? (select all that apply)

White, Black or African-American, Asian, American Indian or Alaska Native, Native Hawaiian or Pacific Islander

Are you Latina or Hispanic?

Yes, No

What is your highest level of education?

Have not earned High School Diploma/GED, High School Diploma/GED, Some college/vocational school, Associate degree, Bachelor degree,

Graduate degree

What is your current work status? (Choose all that apply)

Employed full time, Employed part time, Unemployed, I work at home/homemaker, Disabled, Retired

What is your yearly family income?

$\$ 10,000$ or less; $\$ 10,00$ I to $\$ 20,000$; $\$ 20,00$ I to $\$ 30,000 ; \$ 30,00$ I to $\$ 40,000 ; \$ 40,00$ I to $\$ 50,000$; greater than $\$ 50,000$; do not care to respond

What is your current marital status?

Single/Not Married, Married, Separated, Divorced, Widowed

(Continued) 
Table I (Continued).

\section{Program Satisfaction Questions}

Your county of residence is?

( Answers varied per location of Think Well seminar)

Abbreviation: GED, General Education Development.

\section{Results}

Over four years, the Think Well program had 666 attendees of which 515 (77\% response rate) completed a survey. There were 151 breast cancer survivors, 209 were a family or friend of a breast cancer survivor (co-survivor), and 155 were "other" (eg, health-care professionals, other type of cancer survivor, and interested individuals with no reported relationship with cancer). Table 2 reports the

Table 2 Demographics of Think Well seminar survey $(\mathrm{N}=515)$

\begin{tabular}{|c|c|c|c|}
\hline Variable & $\begin{array}{l}\text { Breast cancer survivors } \\
(n=\mid 5 I)\end{array}$ & $\begin{array}{l}\text { Co-survivors } \\
(n=209)\end{array}$ & $\begin{array}{l}\text { Other attendees } \\
(n=\mid 55)\end{array}$ \\
\hline Age & $61.2 y(S D=10.7)$ & $54.7 y(S D=15.1)$ & $58.7 y(S D=13.8)$ \\
\hline \multicolumn{4}{|l|}{ Race } \\
\hline Black & $62(41.1 \%)$ & $134(64.1 \%)$ & $6 \mathrm{I}(39.4 \%)$ \\
\hline White & $82(54.3 \%)$ & $56(26.8 \%)$ & $84(54.2 \%)$ \\
\hline Other & $0(0.0 \%)$ & I (0.5\%) & $2(1.2 \%)$ \\
\hline Missing & 7 (4.6\%) & $18(8.6 \%)$ & $8(5.2 \%)$ \\
\hline \multicolumn{4}{|l|}{ Ethnicity } \\
\hline Hispanic & $3(2.0 \%)$ & $\mathrm{I}(0.5 \%)$ & I (0.6\%) \\
\hline Non-Hispanic & I $28(84.8 \%)$ & $180(86.1 \%)$ & $143(92.3 \%)$ \\
\hline Missing & $20(13.2 \%)$ & $28(13.4 \%)$ & II (7.I\%) \\
\hline \multicolumn{4}{|l|}{ Education } \\
\hline High school or less & $33(21.9 \%)$ & $37(17.7 \%)$ & 29 (I8.7\%) \\
\hline Some college & $50(33.1 \%)$ & $5 I(24.4 \%)$ & 34 (21.9\%) \\
\hline College degree & $62(41.1 \%)$ & $105(50.2 \%)$ & $84(54.2 \%)$ \\
\hline Missing & $6(4.0 \%)$ & $16(7.7 \%)$ & $8(5.2 \%)$ \\
\hline \multicolumn{4}{|l|}{ Employment } \\
\hline Employed & 47 (31.1\%) & 94 (44.9\%) & 61 (39.3\%) \\
\hline Unemployed/homemaker & $19(12.5 \%)$ & $23(11.0 \%)$ & 14 (9.0\%) \\
\hline retired/disabled & $76(50.3 \%)$ & 78 (37.4\%) & $7 \mid(45.8 \%)$ \\
\hline Missing & $9(6.0 \%)$ & $14(6.7 \%)$ & $9(5.8 \%)$ \\
\hline \multicolumn{4}{|c|}{ Annual family income (US\$) } \\
\hline$\leq \$ 30,000$ & $36(23.8 \%)$ & $62(29.7 \%)$ & $32(20.7 \%)$ \\
\hline$>\$ 30,000$ & 77 (5I.0\%) & $88(42.1 \%)$ & $81(52.2 \%)$ \\
\hline Do not care to respond & $29(19.2 \%)$ & $38(18.2 \%)$ & $28(18.1 \%)$ \\
\hline Missing & $9(6.0 \%)$ & $21(10.0 \%)$ & $14(9.0 \%)$ \\
\hline \multicolumn{4}{|l|}{ Marital status } \\
\hline Single/not married & $4 \mathrm{I}(27.2 \%)$ & $68(32.5 \%)$ & $48(30.9 \%)$ \\
\hline Married & $82(54.3 \%)$ & II $(55.0 \%)$ & $85(54.8 \%)$ \\
\hline Widowed & $21(13.9 \%)$ & $18(8.6 \%)$ & $15(9.7 \%)$ \\
\hline Missing & $7(4.6 \%)$ & $8(3.8 \%)$ & 7 (4.5\%) \\
\hline \multicolumn{4}{|l|}{ Geography } \\
\hline Urban county & $73(48.3 \%)$ & $100(47.8 \%)$ & $84(54.2 \%)$ \\
\hline Rural county & 71 (47.0\%) & $100(47.8 \%)$ & $63(40.6 \%)$ \\
\hline Missing & $7(4.6 \%)$ & $9(4.3 \%)$ & $8(5.2 \%)$ \\
\hline
\end{tabular}


Table 3 Program satisfaction from Think Well seminar survey $(\mathrm{N}=5 \mathrm{I5})$

\begin{tabular}{|c|c|c|c|}
\hline \multirow[t]{2}{*}{ Variable } & $\begin{array}{l}\text { Breast cancer survivors } \\
(n=\mid 5 I)\end{array}$ & $\begin{array}{l}\text { Co-survivors } \\
(n=209)\end{array}$ & $\begin{array}{l}\text { Other attendees } \\
(n=I 55)\end{array}$ \\
\hline & \multicolumn{3}{|c|}{ \% who reported "good" or "excellent" } \\
\hline \multicolumn{4}{|l|}{ Think Well topic } \\
\hline Cognitive changes & $142(96.6 \%)$ & $201(98.6 \%)$ & 146 (95.4\%) \\
\hline Nutrition & $139(95.2 \%)$ & $198(96.6 \%)$ & 149 (96.7\%) \\
\hline Physical activity & 140 (95.9\%) & $199(97.6 \%)$ & 148 (96.1\%) \\
\hline Stress management & $138(94.5 \%)$ & 195 (97.0\%) & 148 (96.7\%) \\
\hline Coping strategies & $137(93.9 \%)$ & $191(95.5 \%)$ & 147 (96.7\%) \\
\hline \multicolumn{4}{|l|}{ Program delivery } \\
\hline Seminar met goals for attending & $137(96.5 \%)$ & $198(99.0 \%)$ & $139(96.5 \%)$ \\
\hline Relevant for cognitive needs & $136(97.1 \%)$ & 194 (97.5\%) & 139 (95.9\%) \\
\hline Relevant to cultural beliefs & 135 (96.5\%) & $193(96.5 \%)$ & 137 (95.8\%) \\
\hline Useful for coping & 137 (97.2\%) & $195(97.0 \%)$ & $138(96.5 \%)$ \\
\hline Useful to communicate cognitive concerns & $138(97.9 \%)$ & $194(97.0 \%)$ & 135 (93.7\%) \\
\hline Refreshments & 137 (96.5\%) & 199 (97.6\%) & 146 (98.0\%) \\
\hline Facilities & 137 (97.9\%) & 200 (98.5\%) & 144 (98.0\%) \\
\hline Overall quality & 139 (98.6\%) & 202 (99.5\%) & I 44 (97.9\%) \\
\hline Likely to recommend Think Well & $142(100.0 \%)$ & 202 (99.5\%) & 148 (100.0\%) \\
\hline
\end{tabular}

demographics of Think Well attendees. Breast cancer survivors were older (61.2 years, SD 10.7), African American (41.1\%), Caucasian (54.3\%), and predominantly nonHispanic. Further, the average length of survivorship was 7.6 years $(\mathrm{SD}=7.7$, range $0-41$ years).

Table 3 reports the program satisfaction of Think Well for breast cancer survivors, co-survivors, and other attendees. Among breast cancer survivors, Think Well received mostly "good" or "excellent" ratings on all educational program components: cognitive changes $(96.6 \%)$, nutrition $(95.2 \%)$, physical activity (95.9\%), stress management (94.5\%), and coping strategies $(93.9 \%)$. Nearly all attendees reported that Think Well met their goals for attending (96.5\%), the material was relevant for cognitive needs $(97.1 \%)$, the material was relevant to their cultural beliefs $(96.5 \%)$, the material was useful for coping (97.1\%), and to communicate cognitive concerns (97.9\%). Further, the content was good/excellent in relation to facilities $(97.9 \%)$ and refreshments (96.5\%). Overall, the quality of Think Well was rated as "good" or "excellent" (98.6\%). The most common format for the desired program format included seminar (as delivered) and online content. Since the Think Well website was added in the second year, the website has attracted $>2,900$ visitors generating $>8,000$ page views over 2.5 years.

Attendees felt that Think well was "very informative," and the "information shared was very valuable." A breast cancer survivor voiced that the program contained "information that [she] can incorporate into [her] daily routine." One older Caucasian breast cancer survivor remarked that she "appreciated applying cognitive strategies to [her] life in general as [she] age[s]." Another attendee recommended that Think Well could "possibly expand commuter outreach at senior centers." A younger African American breast cancer survivor commented that she was "glad chemobrain is a real problem" and "not just in my head."

\section{Discussion}

Overall, Think Well successfully delivered cognitive education to medically underserved areas of Alabama with limited resources. $^{23}$ Attendees reported satisfaction with program seminars reinforced with practical examples and local resources. They also found Think Well to be useful to their cognitive needs. Think Well expanded yearly as attendee feedback was used to adapt the program, including but not limited to development of a website supplementary to the lecture-style program. The website provided continuous education from Think Well's curriculum that attendees could access at any time, which contributes to Think Well's sustainability.

Think Well had many strengths. Think Well was unique in its nature to deliver cognitive changes information to breast cancer survivors and co-survivors. Previous research has demonstrated that breast cancer survivors' 
awareness of cognitive changes depended on health-care settings; ${ }^{26}$ however, Think Well nurses were able to validate patient-reported experiences of cognitive changes, as recommended by the National Comprehensive Cancer Network, through community education. ${ }^{19,25}$ Think Well met the cognitive needs of respective breast cancer communities through delivering tailored education grounded in evidence-based research and provided practical non-pharmacological recommendations for healthy living to mitigate cognitive changes.

Accompanying these strengths were several challenges. Preparation for each seminar required extensive time to build relationships with community leaders, conduct a needs assessment, and jointly prepare for and deliver the Think Well program. The nurse team was diligent in forging relationships with the community leaders. Without the involvement of the community leaders, the Think Well team may have experienced increased difficulty in accessing survivors in the community and subsequent issues in delivering Think Well. Through telephone and in-person meetings with community leaders, the nurse team was able to learn about the community and understand how best to convey and recruit breast cancer survivors to the Think Well program, within the context of each community. Though Think Well's core education curriculum was delivered in each venue, the program was tailored to meet the needs of each individual community. Attendees desired information that was relevant and specific to their community. For example, one community leader asked that information related to cancer screening be delivered along with the Think Well education curriculum. Additionally, attendance varied depending on location of delivery, with higher attendance of breast cancer survivors at cancer centers and, often, a greater proportion of non-breast cancer survivors at non-healthcare locations (eg, churches and community centers).

Another challenge of community-based programs is sustainability. Think Well is no longer delivered in-person due to end of grant funding, but educational content is available on the website. The Think Well website remains operational, and houses tip-sheets and permalinks to Gulf States Young Breast Cancer Survivorship Network (Centers for Disease Control-funded program). ${ }^{27}$ This sustainability plan allows the Think Well program to continue touching the lives of breast cancer survivors throughout Alabama.

While Think Well was targeted to breast cancer survivors, it reached co-survivors and survivors of other underserved cancer populations (eg, prostate, colon, lung).
Many breast cancer survivors felt the need to bring their co-survivors with them so that they would know that cognitive changes are real and "not just in [their] head." Anecdotally, one breast cancer survivor remarked to her husband, "I told you I'm not going crazy!" In response her husband replied, "I believe you now." Survivors of other cancers in attendance, especially at the cancer centers, highlight the need for cognitive changes education across cancer types addressing the lack of resources other cancer survivors. One lung cancer survivor commented, "Everything is about breast cancer. What about us? We matter too." Thus, the Think Well program expanded its reach beyond breast cancer survivors and demonstrated its adaptability to other populations.

Cognitive education is warranted and needed among cancer survivors. Think Well's framework for delivery may be replicated in future community programs. Implications for future community-based, educational programs include: 1) dissemination of education to a national platform towards increasing education and awareness of cognitive changes; 2) using social media as an alternative dissemination venue for cognitive education; and 3) collaboration with health-care professionals to provide timely information on cognitive changes early in survivorship.

\section{Conclusion}

Think Well addressed the needs of cognitive changes among breast cancer survivors in Alabama using evidence-based research and clinical recommendations. A 7-step framework was used to guide program development and delivery, and the program expanded to add online resources using attendee-feedback. Increased community programs and widespread dissemination are necessary to promote cognitive changes awareness and sustainable education.

\section{Acknowledgments}

Dedicated to the memory of Karen Meneses, PhD, RN, FAAN, renowned nurse scientist and beloved Professor and Associate Dean for Research in the University of Alabama at Birmingham School of Nursing, who died suddenly of natural causes on August 1, 2018. She was an internationally recognized pioneering expert in breast cancer survivorship and cancer disparities, and led four years of the program "Think Well: Healthy Living to Improve Cognitive function of Breast Cancer Survivors", supported by Community Grant - Susan G. Komen North 
Central Alabama (CGA-2014-AL100-UNSN73-00004). Think Well was awarded to Dr Karen Meneses by the Susan G. Komen, North Central Alabama Affiliate (CGA-2014-AL100-UNSN73-00004). Authors were supported by additional funding: American Cancer Society Doctoral Degree Scholarship in Cancer Nursing (JBV, TSN, JRB), Susan G. Komen Graduate Traineeship in Disparities Research (JBV, TSN, JRB, KAL, BAH), and Robert Wood Johnson Foundation Future of Nursing Scholarship (JBV, BAH). We would like to acknowledge all of the breast cancer survivors and attendees in the Think Well program for making this possible.

\section{Disclosure}

The authors report no conflicts of interest in this work.

\section{References}

1. National Cancer Institute. Surveillance, epidemiology, and end results program. Cancer stat facts: female breast cancer 2018; Available from: https://seer.cancer.gov/statfacts/html/breast.html. Accessed November 01, 2018.

2. Runowicz CD, Leach CR, Henry NL, et al. American Cancer Society/American Society of Clinical Oncology breast cancer survivorship care guideline. J Clin Oncol. 2016;34(6):611-635. doi:10.1200/JCO.2015.64.3809

3. Myers JS. Chemotherapy-related cognitive impairment: the breast cancer experience. Oncol Nurs Forum. 2012;39(1):E31-E40. doi:10.1188/12.ONF.E31-E40

4. Player L, Mackenzie L, Willis K, Loh SY. Women's experiences of cognitive changes or 'chemobrain' following treatment for breast cancer: a role for occupational therapy? Aust Occup Ther J. 2014;61(4):230-240. doi:10.1111/1440-1630.12113

5. Ahles TA, Saykin AJ, McDonald BC, et al. Longitudinal assessment of cognitive changes associated with adjuvant treatment for breast cancer: impact of age and cognitive reserve. J Clin Oncol. 2010;28 (29):4434-4440. doi:10.1200/JCO.2009.27.0827

6. Ahles TA, Root JC, Ryan EL. Cancer- and cancer treatment-associated cognitive change: an update on the state of the science. J Clin Oncol. 2012;30(30):3675-3686. doi:10.1200/JCO.2012.43.0116

7. Ahles TA, Saykin AJ. Candidate mechanisms for chemotherapyinduced cognitive changes. Nat Rev Cancer. 2007;7(3):192-201. doi:10.1038/nrc2073

8. Fallowfield L, Jenkins V. Psychosocial/survivorship issues in breast cancer: are we doing better? J Natl Cancer Inst. 2015;107(1):335. doi:10.1093/jnci/dju335

9. Frank JS, Vance DE, Jukkala A, Meneses KM. Attention and memory deficits in breast cancer survivors: implications for nursing practice and research. J Neurosci Nurs. 2014;46(5):274-284. doi:10.1097/ JNN.0000000000000078

10. Hodgson KD, Hutchinson AD, Wilson CJ, Nettelbeck T. A meta-analysis of the effects of chemotherapy on cognition in patients with cancer. Cancer Treat Rev. 2013;39(3):297-304. doi:10.1016/j.ctrv.2012.11.001

11. Phillips KM, Jim HS, Small BJ, Laronga C, Andrykowski MA, Jacobsen PB. Cognitive functioning after cancer treatment: a 3-year longitudinal comparison of breast cancer survivors treated with chemotherapy or radiation and noncancer controls. Cancer. 2012;118 (7):1925-1932. doi:10.1002/cncr.26432
12. Vance ID, Larsen AK, Eagerton AG, Wright AM. Comorbidities and cognitive functioning: implications for nursing research and practice. J Neurosci Nurs. 2011;43(4):215-224. doi:10.1097/ JNN.0b013e3182212a04

13. Vance ED, Heaton LK, Eaves LY, Fazeli LP. Sleep and cognition on everyday functioning in older adults: implications for nursing practice and research. J Neurosci Nurs. 2011;43(5):261-271. doi:10.1097/ JNN.0b013e318227 efb2

14. Vance DE. Potential factors that may promote successful cognitive aging. Nurs Res Rev. 2012;2:27.

15. Vance DE, Fazeli PL, Kaur J, Pearce P, McGuinness T. Neuropsychology and cognitive health in healthy older adults: A brief overview for psychiatric nurses. $J$ Psychosoc Nurs Ment Health Serv. 2012;50(6):30-37; quiz 46-37. doi:10.3928/0279369520120508-03

16. Vance D, Eagerton G, Harnish B, McKie P, Fazeli PL. Cognitive prescriptions: A nursing approach to increasing cognitive reserve. J Gerontol Nurs. 2011;34(4):22-29. doi:10.3928/00989134-200 80601-11

17. Vance D, Gakumo C, Childs G, Enah C, Fazeli PL. Feedback on a multimodal cognitive intervention for adults aging with HIV: A focus group study. J Assoc Nurses AIDS Care. 2017;28(5):685-697. doi:10.1016/j.jana.2017.06.002

18. Vance DE, Frank JS, Bail J, et al. Interventions for cognitive deficits in breast cancer survivors treated with chemotherapy. Cancer Nurs. 2017;40(1):E11-E27. doi:10.1097/NCC.0000000000000349

19. National Comprehensive Cancer Network. NCCN Clinical Practice Guidelines in Oncology (NCCN Guidelines ${ }^{\circledR}$ ): survivorship [v.3.2018]. 2018; Available from: https://www.nccn.org/profes sionals/physician_gls/pdf/survivorship.pdf. Accessed November 01, 2018.

20. Bowen DJ, Kreuter M, Spring B, et al. How we design feasibility studies. Am J Prev Med. 2009;36(5):452-457. doi:10.1016/j. amepre.2009.02.002

21. Breast cancer survivorship rehabilitation initiative. Community Report. 2015.

22. American Cancer Society. Cancer facts and figures 2018. 2018; Available from: https://www.cancer.org/content/dam/cancer-org/ research/cancer-facts-and-statistics/annual-cancer-facts-and-figures/ 2018/cancer-facts-and-figures-2018.pdf. Accessed November 01, 2018.

23. Susan G Komen North Central Alabama. Community Profile Report. 2015; Available from: http://komenncalabama.org/wp-content/ uploads/2012/08/Komen-North-Central-Alabama-2015-CommunityProfile-Report.pdf. Accessed November 01, 2018.

24. Bail J, Nolan TS, Vo JB, Gisiger-Camata S, Meneses K. Engaging an urban african american community to deliver cognitive health education to breast cancer survivors. J Cancer Educ. 2016;33(4):870-874. doi:10.1007/s13187-016-1155-6

25. Vo JB, Nolan TS, Bail JR, Gisiger-Camata S, Meneses K. Cognitive changes: educating breast cancer survivors with the Think Well: healthy living to improve cognitive function program. Clin J Oncol Nurs. 2018;22(3):252-255. doi:10.1188/18.CJON.252-255

26. Selamat MH, Loh SY, Mackenzie L, Vardy J. Chemobrain experienced by breast cancer survivors: A meta-ethnography study investigating research and care implications. PLoS One. 2014;9(9): e108002-e108002. doi:10.1371/journal.pone.0108002

27. Williams DL, Nolan TS, Chiu Y-W, et al. A partnership in healthrelated social media for young breast cancer survivors. Health Promot Pract. Epub 2018 Sep 25. 


\section{Publish your work in this journal}

Nursing: Research and Reviews is an international, peer-reviewed, open access journal publishing original research, reports, reviews and commentaries on all aspects of nursing and patient care. These include patient education and counseling, ethics, management and organizational issues, diagnostics and prescribing, health outcomes,

economics and resource management, improving patient safety in all settings. The manuscript management system is completely online and includes a very quick and fair peer-review system. Visit http://www. dovepress.com/testimonials.php to read real quotes from published authors.

Submit your manuscript here: http://www.dovepress.com/nursing-research-and-reviews-journal 